\title{
ANÁLISIS
}

\section{China en el Caribe: estrategia diplomática y de negocios ${ }^{1}$}

DOI: $10.32870 /$ mycp.v15i43.377

Gabriela Correa López ${ }^{2}$

\section{Resumen}

L

a presencia de la República Popular China (China) en casi todas las regiones del mundo corresponde a una estrategia amplia y de largo plazo que busca principalmente asegurar el abastecimiento de insumos, abrir mercados a sus productos y lograr un reconocimiento a su condición de país responsable en el ámbito internacional.

El impacto de la presencia China adquiere variados matices y áreas de acción, que incluyen comercio, inversión, cooperación, ayuda económica, ayuda humanitaria e intercambios culturales, así como también una sistemática persecución contra Taiwán para evitar que logre reconocimientos internacionales.

En este trabajo se presenta en primer lugar la situación económica de los países del Caribe, particularmente los agrupados en Caricom. En un segundo apartado se discute el tipo de acciones que tiene la presencia de China en los países del Caribe señalando la variedad de relaciones y experiencias logradas en los países y en las instituciones regionales. Finalmente, se discuten algunos elementos del debate respecto a la interpretación de la presencia china en la región.

Palabras clave: China, Caribe

1. Artículo recibido el 14 de septiembre de 2011 y dictaminado el 11 de noviembre de 2011.

2. Profesora-investigadora de la Universidad Autónoma Metropolitana, Campus Iztapalapa, gcl@xanum.uam.mx, San Rafael Atlixco 186, Colonia Vicentina, Iztapalapa, México, df. ORCID http://orcid.org/0000-0001-5725-3496 


\section{Abstract}

The presence of the People's Republic of China (China) in almost all regions of the world corresponds to a comprehensive and long-term strategy, mainly to ensure the supply of inputs, open markets for their products and achieve recognition of its status as a responsible country in the international arena.

The impact of China's presence in Caribbean countries takes on various hues and action areas, including trade, investment, cooperation, economic aid, humanitarian assistance and cultural exchanges, as well as a systematic persecution of Taiwan in terms of international recognition dispute.

This paper discusses the economic situation of the Caribbean countries, particularly those grouped in Caricom. The second section discusses the types of actions that the presence of China in the Caribbean, pointing to the variety of relationships and experiences gained in the countries and regional institutions. Finally discuses some elements on the debate regarding the interpretation of China's presence in the region.

Keywords: China, Caribbean

\section{Presentación}

La República Popular China (China) mantiene una presencia con distintos grados de relevancia con los países del Caribe y con todos los que sostiene relaciones diplomáticas encuentra áreas de negocios, cooperación y apoyo en temas internacionales. En el caso de aquellos países caribeños con los que no tiene relaciones diplomáticas, opera sus relaciones comerciales a través de representaciones de negocios permanentes.

La presencia de China en los países del Caribe es parte de su estrategia internacional que incluye asegurar abastecimiento de insumos, mercados para sus productos así como respaldo para sus proyecciones internacionales como país responsable y parte del grupo de naciones en línea con una defensa de intereses de países subdesarrollados, con un liderazgo que le asegura ventajas en la persecución de sus objetivos nacionales (Correa, 2009: 203-228; González y Correa, 2009: 979-993).

China también encuentra en instituciones oficiales, asociaciones empresariales y gobiernos de países del Caribe algunos foros para insistir en la superioridad de lo que identifica como su modelo económico - fuerte intervención estatal y gobierno autoritario- como un ejemplo de lo que 
otros países subdesarrollados podrían lograr. Si bien insiste en su ascenso pacífico y su negativa a exportar experiencias, en el fondo está ofreciendo la posibilidad de "nuevos milagros" para el crecimiento económico mientras que al mismo tiempo construye palancas para aumentar su capacidad de negociación internacional y afectar a su favor las relaciones de poder mundiales.

China ha establecido importantes relaciones institucionales en América Latina a través del Banco Interamericano de Desarrollo (BID) y la Comisión Económica para América Latina y el Caribe (CEPAL). En el primer organismo fue aceptado como miembro en el año 2009 y ha canalizado recursos crediticios y fondos de ayuda. La CEPAL subrayó recientemente la importancia del XII Plan Quinquenal de China, que propone reorientar su crecimiento a la expansión del mercado doméstico, ${ }^{3}$ lo que ofrecería oportunidades de comercio para algunos países de América Latina y el Caribe (CEPAL, 2011).

China ha adquirido importancia como promotor de la integración productiva regional en el Sudeste de Asia ${ }^{4}$ así como mediante su participación en esquemas intercontinentales de integración como el mecanismo APEC. Esta importancia es reconocida por grupos de países de América Latina y el Caribe que mantienen iniciativas como el Foro del Arco Pacífico Latinoamericano,

3. China requiere importar insumos para mantener su actividad productiva y estar en capacidad de abastecer la expansión de su mercado doméstico con manufacturas. Con este fin ha construido una integración regional y extra regional para asegurar su abastecimiento de productos minerales, energéticos y alimentos.

4. Particularmente con ASEAN. 
así como por Chile, Costa Rica y Perú que han firmado acuerdos bilaterales de comercio con China.

En este artículo se presenta en primer lugar un breve recuento de la situación económica de los países del Caribe, particularmente los agrupados en Caricom. En una segunda parte se analizan las características de las acciones que tiene la presencia de China en los países del Caribe, señalando la variedad de relaciones y experiencias. Finalmente se discuten algunos elementos del debate respecto a la interpretación de la presencia china en la región.

\section{Los países en el Caribe}

Los países en el Caribe comparten una experiencia histórica de dominio colonial, además de su contacto a través del océano que los distingue geográficamente en Antillas Mayores, Antillas Menores y parte del continente Sudamericano (véase mapa 1).

El tamaño de sus economías y sus limitados recursos territoriales -en la mayor parte de los casos- han resultado en una experiencia que busca establecer, a través de su integración en Caricom, una economía y mercado únicos con moneda común en el futuro. ${ }^{5}$

La historia de los países del Caribe los relaciona con Francia, Reino Unido, Estados Unidos y Holanda. Con el transcurso de los años, este pasado se ha convertido en preferencias comerciales que son decisivas en el destino de las exportaciones. En la mayor parte de las economías los servicios turísticos y financieros son las principales categorías de actividad económica, además de las relacionadas con petróleo en Trinidad y Tobago.

También están en esta región otros países como Cuba, Puerto Rico, República Dominicana, Bermudas e Islas Vírgenes Británicas, que tienen historias y economías particulares, con características diversas como ser, respectivamente, una economía centralmente controlada, un Estado asociado a Estados Unidos u operar como territorios de referencia para el reciclado internacional de capitales (véase cuadro 1 en el anexo).

5. Caricom: 15 países miembros: Antigua y Barbuda, Bahamas, Barbados, Belice, Dominica, Granada, Guyana, Haití, Jamaica, Montserrat, Saint Kitts y Nevis, Santa Lucía, San Vicente y Las Granadinas, Suriname, Trinidad y Tobago. Seis países asociados: Anguila, Bermudas, Islas Vírgenes Británicas, Islas Caimán, Islas Turcos y Caicos. 
La diversidad de condiciones de los países en el Caribe coincide con los tipos de relaciones que han establecido con China, incluyendo la ausencia de relaciones diplomáticas al no reconocer la política de "una China" y mantener el reconocimiento a la República de China (Taiwán), que son los casos de Santa Lucía, Belice y República Dominicana. De esta forma China tiene una presencia diversa en términos de relaciones bilaterales así como en materia de participación en instituciones regionales y en coincidencias estratégicas de largo plazo, en particular la construcción de relaciones internacionales multipolares, en donde la importancia de Estados Unidos tienda a disminuir.

Entre los países en el Caribe, un acuerdo significativo en materia energética es Petrocaribe, ${ }^{6}$ mediante el cual la República Bolivariana de Venezuela (RB de Venezuela) desde el año 2005 abastece de petróleo y otros productos en condiciones preferentes a los países asociados y promueve proyectos para el desarrollo a través del Foro Alba Caribe. La importancia, además del abasto en condiciones preferenciales de recursos energéticos, es la cooperación política en la búsqueda por relaciones internacionales multipolares que cuestionen la dominación de Estados Unidos, en un discurso explícito y duro que encabeza la RB de Venezuela.

La experiencia de integración de Caricom desde 1973 ha ofrecido a los países miembros la posibilidad de superar limitaciones de recursos, de escala y mercados. Dentro de esta organización se incluye la Organización de Estados del Caribe Occidental (OECO) que agrupa siete economías, incluyendo una dependencia territorial del Reino Unido. ${ }^{7}$

El objetivo de lograr un mercado y economía únicos en Caricom está previsto para el año 2015, pero entretanto se promueven acuerdos de cooperación con otras regiones como el Acuerdo de Asociación Económica con la Unión Europea que entró en vigor en el año 2008 y que forma parte de los apoyos que la integración de la región caribeña recibe. La relación comercial central además de la intra-regional es la mantenida con Estados Unidos que a partir de la Iniciativa de la Cuenca del Caribe otorga preferencias comerciales a países de la región.

6. Miembros de Petrocaribe: Antigua y Barbuda, Bahamas, Belice, Cuba, Dominica, Jamaica, República Dominicana, Saint Kitts y Nevis, Granada, San Vicente y Granadinas, Santa Lucía, Guyana, Suriname, Haití, Honduras, Guatemala y RB de Venezuela.

7. OECO: Antigua y Barbuda, Dominica, Grenada, Montserrat, Saint Kitts y Nevis, Santa Lucía, San Vicente y Granadinas. 
República Dominicana mantiene un acuerdo conocido como CAFTA (Centroamérica y Estados Unidos) por el cual recibe preferencias comerciales y aunque sostiene proyectos de cooperación y comercio con Caricom, hay diferencias respecto a ritmos y estilos de liberalización comercial.

La principal característica de los países en el Caribe es la diversidad, lo cual se percibe al interior de Caricom. Las diferencias en los recursos y evolución de las economías en Caricom son significativas; por ejemplo en la tabla 1 se confirma la importancia de Jamaica así como la de Trinidad y Tobago en términos del PIB y de las exportaciones de bienes. Si se considera la exportación de servicios, Jamaica, Bahamas y Barbados registran los tres primeros lugares en importancia.

\section{Tabla 1}

Caricom: participación de sus miembros en el PIB total, exportación de bienes y de servicios (en porcentaje)

\begin{tabular}{llllllllll}
\hline & \multicolumn{3}{c}{ Producto interno bruto } & \multicolumn{3}{c}{ Exportación de bienes } & \multicolumn{3}{c}{ Exportación de servicios } \\
\cline { 2 - 10 } & 1990 & 2000 & 2008 & 1990 & 2000 & 2008 & 1990 & 2000 & 2008 \\
\hline Jamaica & 22.3 & 26.1 & 20.6 & 22.7 & 18.5 & 9.4 & 23.5 & 27.5 & 26.4 \\
Trinidad y Tobago & 21.7 & 23.8 & 38.2 & 37.4 & 50.7 & 70.5 & 7.5 & 7.5 & 8.7 \\
Bahamas & 15.0 & 16.0 & 10.7 & 5.4 & 5.5 & 3.6 & 34.3 & 26.8 & 24 \\
Suriname & 7.7 & 2.3 & 3.4 & 15.9 & 4.7 & 6.5 & 0.8 & 1.2 & 2.7 \\
Barbados & 7.4 & 7.5 & 5.2 & 4.2 & 3.3 & 1.7 & 15.0 & 13.8 & 15.5 \\
Belice, Guyana y & 19.2 & 16.4 & 15.4 & 7.5 & 13.2 & 6.6 & 3.8 & 6.7 & 8.9 \\
Haití & & & & & & & & & \\
OEco (a) & 6.7 & 8.0 & 6.5 & 6.9 & 4.1 & 1.7 & 15.1 & 16.4 & 13.8 \\
\hline
\end{tabular}

(a) Antigua y Barbuda, Dominica, Grenada, Montserrat, Saint Kitts y Nevis, Santa Lucía, San Vicente y Granadinas. $<$ R>Fuente: CEPAL, Panorama de la inserción internacional de América Latina y el Caribe 2010-2011. Crisis originada en el centro y recuperación impulsada por las economías emergentes, Santiago de Chile, agosto de 2010.

Los últimos treinta años han mostrado las grandes diferencias productivas entre los países del Caribe y los de América Latina, lo cual se refleja en el comercio exterior. Si se considera - como en la tabla 2- las exportaciones de bienes en la agregación del total de América Latina y el Caribe, se percibe una significativa recuperación de la exportación de bienes en la década de los años 1990, con un leve deterioro en la década siguiente, que identifica el deterioro de las exportaciones de México. Esta evolución es distinta para el 
Caribe: de una disminución en la década de 1980 pasa a recuperarse en los siguientes dos decenios hasta llegar a un crecimiento de $4.5 \%$ en los últimos años, mostrando una mejoría que tiene relación con el aumento del comercio al interior de los países en Caricom.

Si se consideran las importaciones en el total agregado de América Latina y el Caribe, se registra un movimiento similar en las tres décadas comentadas; de tasas decrecientes en los años 1980 se pasa a tasas que crecen alrededor de $10 \%$ en los años 1990 y que disminuyen en la década siguiente refiriendo una reducción de importaciones. Los países del Caribe tienen tasas decrecientes respecto a importaciones en la década de 1980 que crecen en las siguientes dos décadas. En los últimos años se ha mantenido la asimetría entre los países del Caribe y los del resto del continente; por ejemplo, la recuperación de las exportaciones en el año de 2010 fue de casi el doble en América Latina que en el Caribe, en tanto las importaciones fueron solo una décima parte.

En general el comercio de China con América Latina y el Caribe ha sido dinámico y representa $6 \%$ del total del comercio chino, pero es deficitario para el conjunto del continente. En el periodo 2005 a 2010 las exportaciones totales crecieron $31 \%$ en tanto las importaciones lo hicieron a $28 \%$. El déficit resultante expresa la penetración de mercados domésticos y la competencia en terceros mercados. China es el principal destino de las exportaciones de Cuba (29\% de su total), Chile (27\% de de su total), Perú (17\% de de su total), Brasil (17\% de su total), Argentina (9\% de su total) y RB de Venezuela (9\% de su total). En el extremo son altos importadores desde China: Paraguay (35\% de su total), Antigua y Barbuda (44\%), México (18\%), Chile (17\%), Brasil (16\%), Argentina (15\%), Uruguay (15\%), Cuba (12\%), República Dominicana (11\%), San Vicente y Granadinas (6\%) y Haití (7\%) (CEPAL, 2011). Estas cifras reflejan el impacto de las importaciones desde China, principalmente manufactureras, en los mercados domésticos lo cual significa presiones a la actividad productiva y al empleo doméstico, que por efecto del propio tamaño de la planta productiva adquiere connotaciones distintas para países como Brasil o Haití.

La presencia china se resiente en las economías del continente y afecta sus proyectos de industrialización y comercio, de ahí que las propuestas de formar cadenas de valor con empresas chinas deban ser discutidas con mayor información, reconociendo que el Sudeste Asiático es el área de integración regional de China donde tiene un mayor avance. 
En resumen, respecto a exportaciones de bienes los países del Caribe tienen un comportamiento distinto al del resto de países en América Latina, lo que puede explicarse por el aumento de los flujos de comercio en los países de mayor tamaño.

\section{Tabla 2}

América Latina y el Caribe. Evolución del comercio de servicios (tasas medias anuales de crecimiento calculadas sobre la base de dólares corrientes)

\begin{tabular}{|c|c|c|c|c|c|c|c|c|}
\hline & \multicolumn{4}{|c|}{ Exportaciones } & \multicolumn{4}{|c|}{ Importaciones } \\
\hline & $\begin{array}{l}1980- \\
1989\end{array}$ & $\begin{array}{l}1990- \\
1999\end{array}$ & $\begin{array}{l}2000- \\
2009\end{array}$ & 2010 & $\begin{array}{l}1980- \\
1989\end{array}$ & $\begin{array}{l}1990- \\
1999\end{array}$ & $\begin{array}{l}2000- \\
2009\end{array}$ & 2010 \\
\hline $\begin{array}{l}\text { América Latina y el } \\
\text { Caribe }\end{array}$ & 4.6 & 6.7 & 7.3 & 26.7 & 0.4 & 6.8 & 7.2 & 29.5 \\
\hline $\begin{array}{l}\text { América Latina y el } \\
\text { Caribe (Sin México) }\end{array}$ & 4.4 & 7.6 & 8.7 & 27.0 & -0.1 & 7.9 & 8.0 & 30.4 \\
\hline Caribe & 7.7 & 8.8 & 5.9 & 10.8 & 2.4 & 6.2 & 3.2 & 3.5 \\
\hline
\end{tabular}

Fuente: CEPAL, Panorama de la inserción internacional de América Latina y el Caribe, 2010; CEPAL, Panorama de la inserción internacional de América Latina y el Caribe, 2011.

Si se considera la evolución del comercio de servicios en el agregado de América Latina y el Caribe y el propio Caribe en las tres últimas décadas (que se incluyen en la tabla 3), se confirma el distinto comportamiento en ambos agregados, ya que al aumento de exportaciones en América Latina en todo el periodo, corresponde una elevación hasta 1999 y una reducción de casi tres puntos porcentuales en los últimos años en el Caribe. Respecto a importaciones las distintas trayectorias se distinguen al estar al alza en América Latina y el Caribe y una disminución de tres puntos porcentuales en el Caribe. Se reproduce un patrón diferenciado entre ambos agregados, lo cual puede explicarse por la importancia del comercio de servicios en el Caribe y el deterioro de la actividad económica en la última década.

En Trinidad y Tobago, Suriname y Jamaica existen sectores productivos significativos en comparación con el resto de países en el Caribe, lo cual los convierte en economías exportadoras de bienes y servicios. En el extremo está Haití, que ha padecido catástrofes políticas y naturales y que a pesar de su larga historia independiente se mantiene como la economía más pobre 


\section{Tabla 3}

América Latina y el Caribe. Evolución del comercio de servicios (tasas medias anuales de crecimiento calculadas sobre la base de dólares corrientes)

\begin{tabular}{lcccccc}
\hline & \multicolumn{3}{c}{ Exportaciones } & \multicolumn{3}{c}{ Importaciones } \\
\cline { 2 - 7 } & $1980-$ & $1990-$ & $2000-$ & $1980-$ & $1990-$ & $2000-$ \\
& 1989 & 1999 & 2009 & 1989 & 1999 & 2009 \\
\hline América Latina y el Caribe & 4.6 & 6.7 & 7.3 & 0.4 & 6.8 & 7.2 \\
América Latina y el Caribe (Sin & 4.4 & 7.6 & 8.7 & -0.1 & 7.9 & 8.0 \\
México) & & & & & & \\
Caribe & 7.7 & 8.8 & 5.9 & 2.4 & 6.2 & 3.2 \\
\hline
\end{tabular}

Fuente: CEPAL, Panorama de la inserción internacional de América Latina y el Caribe 2010-2011.

Crisis originada en el centro y recuperación impulsada por las economías emergentes, Santiago de Chile, agosto, 2010.

del continente, no obstante la ayuda exterior, emigración y cooperación internacional. En Haití en los últimos años se ha asentado un grupo de establecimientos maquiladores textiles con exportaciones hacia Estados Unidos, que a pesar del terremoto de enero de 2010 restablecieron sus actividades con rapidez, lo cual es poco significativo frente a la destrucción económica y social todavía imperante.

Jamaica, Barbados y Bahamas son receptores de turismo y en menor medida de servicios financieros, actividades que se han mantenido en los últimos años a pesar de la contracción económica global. Guyana y Suriname son exportadores de productos básicos a la región y fuera de ella, con una base importante en recursos naturales. El resto de los países se mantiene estancado a pesar de las preferencias comerciales y el estancamiento se atribuye a los altos costos de energía, la liberalización comercial y el impacto de otros países en la producción manufacturera, especialmente China.

El patrón productivo de los países en el Caribe está concentrado en pocas actividades y productos. Jamaica exporta metales a Estados Unidos, la Unión Europea y Asia. Barbados y Bahamas exportan en la región productos básicos, alimentos a la Unión Europea y manufacturas ligeras hacia Estados Unidos. Las islas en la OECO exportan manufacturas y piezas eléctricas, a partir de plantas maquiladoras, hacia Estados Unidos.

Como puede apreciarse en la tabla 4, la importancia de productos energéticos es decisiva en las exportaciones de Caricom, particularmente aso- 
ciadas a las actividades de Trinidad y Tobago y están concentradas en pocos productos. Si se consideran las diez principales categorías de exportaciones, se aprecia que representan $72 \%$ del total de exportaciones, lo cual muestra escasa diversificación.

\section{Tabla 4}

Caricom. Valor de las diez primeras categorías de exportaciones, 2008

\begin{tabular}{lcc}
\hline Mercancías & $\begin{array}{c}\text { Valor (millones } \\
\text { de dólares) }\end{array}$ & $\begin{array}{c}\text { Proporción del total } \\
\text { de exportaciones, \% }\end{array}$ \\
\hline Gas natural licuado & $4,875.8$ & 22.1 \\
$\begin{array}{l}\text { Otros productos de petróleo y productos obtenidos } \\
\text { de minerales bituminosos, crudos }\end{array}$ & $2,214.5$ & 10.0 \\
Anhidro amoniaco & $1,788.8$ & 8.1 \\
Otros productos de petróleo y productos obtenidos & $1,544.0$ & 7.0 \\
de minerales bituminosos y preparaciones, no & & \\
especificados & & 6.7 \\
Aceites del gas (distintos del diesel) & $1,479.3$ & 5.6 \\
Óxido de aluminio (alúmina), diferentes del corindón & $1,229.2$ & 4.8 \\
Metanol (alcohol metílico) & $1,062.0$ & 4.5 \\
Keroseno tipo combustible de avión & 999.7 & 4.4 \\
Gasolina para automóviles & 972.8 & 1.8 \\
Otros gases líquidos de petróleo y otros gases de & 406.6 & \\
hidrocarburos & & \\
\hline Valor total de las 10 primeras categorías de & $16,572.7$ & \\
exportaciones & & \\
Valor del total de exportaciones & $22,069.8$ & \\
\hline
\end{tabular}

Fuente: Caricom, Estadísticas 2004-2008.

Por lo que corresponde a las importaciones, como se puede apreciar en la tabla 5 , los productos energéticos y algunos químicos resultan de relevancia y son casi la tercera parte del total de importaciones. Esta estructura de importaciones ratifica la dependencia de productos energéticos y la importancia que Petrocaribe tiene para la región.

El análisis de los principales socios comerciales de Caricom para el año 2008 (tabla 6) muestra la importancia de Estados Unidos, con 31.7\% de las importaciones y $41.5 \%$ de las exportaciones. Entre los países de origen de las importaciones están los petroleros (Venezuela y Gabón) y los manufac- 


\section{Tabla 5}

Caricom. Valor de las diez primeras categorías de importaciones, 2008

\begin{tabular}{lcc}
\hline Mercancías & $\begin{array}{c}\text { Valor (millones } \\
\text { de dólares) }\end{array}$ & $\begin{array}{c}\text { Proporción del total } \\
\text { de importaciones, \% }\end{array}$ \\
\hline $\begin{array}{l}\text { Otros productos de petróleo y productos obtenidos de } \\
\text { minerales bituminosos, crudos }\end{array}$ & $3,132.3$ & 12.7 \\
Búnker petróleo grado C & $1,377.6$ & 5.6 \\
Gasolina para automóviles & 948.7 & 3.8 \\
Gasóleo & 930.2 & 3.8 \\
$\begin{array}{l}\text { Otros productos de petróleo y productos obtenidos } \\
\text { de minerales bituminosos crudo, importados bajo }\end{array}$ & 881.6 & 3.6 \\
$\begin{array}{l}\text { acuerdos de procesamiento } \\
\text { Alcohol etílico desnaturalizado de fuerza alcohólica }\end{array}$ & 301.5 & 1.2 \\
por volumen de 80\% o superior & & 1.1 \\
Planta de destilación o rectificación & 271.9 & 1.1 \\
$\begin{array}{l}\text { Minerales de hierro y concentrados, distintos de } \\
\text { piritas de hierro tostadas, aglomerados. }\end{array}$ & 267.3 & \\
Otros libros impresos, folletos y similares impresos. & 242.8 & 1.0 \\
Otras estructuras y partes de estructuras, de hierro o & 236.3 & 1.0 \\
acero. & & \\
\hline $\begin{array}{l}\text { Valor total de las 10 primeras categorías de } \\
\text { importaciones }\end{array}$ & $8,590.1$ & \\
Valor del total de importaciones & & \\
\hline
\end{tabular}

Fuente: Caricom, Estadísticas 2004-2008.

tureros en la región y fuera de ella. China aparece como el quinto socio de importancia en 2008.

\section{Presencia de China en los países del Caribe}

China mantiene en el Caribe tratamientos diferentes, que incluyen acciones en varias áreas de su espectro de intereses. China fue aceptada en enero de 2009 como el miembro número 48 en el BID, aportando recursos al financiamiento del desarrollo para los países miembros de América Latina y el Caribe. ${ }^{8}$

8. El BID tiene 48 miembros de los cuales reciben financiamiento 26. Los 26 prestatarios forman parte de la Organización de Estados Americanos y del Fondo Monetario Internacional. Los 
Tabla 6

Caricom. Principales socios comerciales, 2008

\begin{tabular}{|c|c|c|}
\hline Socio comercial & $\begin{array}{l}\text { Valor del comercio } \\
\text { (millones de dólares) }\end{array}$ & $\%$ \\
\hline \multicolumn{3}{|l|}{ Importaciones } \\
\hline Estados Unidos & $7,853.3$ & 31.7 \\
\hline Trinidad y Tobago & $2,593.8$ & 10.5 \\
\hline Brasil & $1,442.2$ & 5.8 \\
\hline Venezuela & 1439.5 & 5.8 \\
\hline China & $1,122.9$ & 4.5 \\
\hline Colombia & 860.0 & 3.5 \\
\hline Japón & 744,3 & 3.0 \\
\hline Reino Unido & 589.6 & 2.4 \\
\hline Gabón & 588.3 & 2.4 \\
\hline Alemania & 553.1 & 2.2 \\
\hline Subtotal & $17,787.2$ & 71.9 \\
\hline Total de importaciones & $24,746.0$ & 100 \\
\hline \multicolumn{3}{|l|}{ Exportaciones } \\
\hline Estados Unidos & $9,158.9$ & 41.5 \\
\hline Jamaica & $1,311.8$ & 5.9 \\
\hline España & $1,179.0$ & 5.3 \\
\hline Reino Unido & 801.8 & 3.6 \\
\hline Países Bajos & 780.3 & 3.5 \\
\hline Canadá & 671.9 & 3.0 \\
\hline México & 603.1 & 2.7 \\
\hline Barbados & 583.5 & 2.6 \\
\hline República Dominicana & 530.0 & 2.4 \\
\hline Suriname & 451.0 & 2.0 \\
\hline Subtotal & $16,071.7$ & 72.8 \\
\hline Total de exportaciones & $22,069.7$ & 100 \\
\hline
\end{tabular}

Fuente: Caricom, Estadísticas 2004-2008.

Coincidiendo con la sesión del Aniversario 50 del BID se firmó, en octubre de 2010, un acuerdo con China que aportó recursos importantes para apoyar acciones sobre todo de facilitación del comercio, en el cual Eximbank de China

miembros fuera de la región que aportan recursos pertenecen a la Corporación Interamericana de Inversiones o al Fondo Multilateral de Inversiones. 
se comprometió a aportar cofinanciamientos de hasta 200 millones de dólares en un periodo de dos años.

El BID reconoce que Eximbank de China es un canal fundamental de política financiera en relación con las importaciones y exportaciones chinas de productos mecánicos y electrónicos, paquetes de equipamiento, productos de alta y nueva tecnología, así como para la obtención de contratos de construcción y la realización de proyectos de inversión en el extranjero por parte de empresas chinas. ${ }^{9}$

China ha organizado conferencias de empresarios y negocios como puntal para cimentar sus relaciones de negocios con países en el Caribe. La primera reunión se realizó en Kingston en 2005. La segunda y más importante de estas conferencias se realizó en el año 2007 en Xiamen, China.

El Segundo Foro China y Caribe de Cooperación Económica y Comercio se realizó en Xiamen con la asistencia de delegaciones de Antigua y Bermuda, Bahamas, Barbados, Dominica, Grenada, Guyana, Suriname, Trinidad y Tobago, y Jamaica, así como otros participantes de República Dominicana, Haití, Sta. Lucía, Caricom y el Banco de Desarrollo del Caribe. La misión de negocios firmó la Declaración de Xiamen en busca de consolidar la asociación comercial y particularmente "para apoyar el convencimiento a los responsables de economía y comercio de la importancia de la cooperación" (People's Republic of China, 2007).

En el año 2010, junto con el BID se patrocinó una reunión de negocios en Chengdu que congregó nuevamente a grupos empresariales y de negocios en un ejercicio de acercamiento y promoción del comercio.

Esta Declaración de Xiamen precedió el documento Políticas hacia América Latina y el Caribe que el gobierno central de China publicó a finales de 2008. Este documento plantea los objetivos de relaciones económicas y diplomáticas así como los principios de cooperación y respeto mutuo. El documento se convirtió en el segundo esfuerzo de China por explicitar sus principios de relaciones con otras regiones del mundo, considerando que años antes había publicado los correspondientes a las relaciones con África. El único requisito para el mantenimiento de relaciones diplomáticas es el reconocimiento a la política de "una sola China", que es parte de las acciones de contención hacia Taiwán.

9. “IDB-China Eximbank join forces to set up infrastructure facility and public-private investment fund in Latin America and Caribbean", News releases, marzo 28, 2011. 
En septiembre de 2011 se realizó en Puerto España, Trinidad y Tobago el Tercer Foro de Cooperación y Comercio Caribe-China. En el evento se acordaron recursos por mil millones de dólares para seis proyectos de desarrollo, becas para entrenamiento técnico y estudios de posgrado en China, así como el aporte de un millón de dólares para el Fondo de Desarrollo del Caribe.

En el extremo de excelentes relaciones de China con países del Caribe está Cuba. China es el segundo socio comercial de Cuba y mantiene una larga tradición de amistad y cooperación a partir de la afinidad ideológica y política, a pesar de que la ortodoxia del gobierno cubano recibe un mesurado distanciamiento político de los gobernantes chinos. La cooperación económica, tecnológica y militar está en el tope de las relaciones bilaterales ya que comercio e inversión no son el eje de la relación. Los últimos acuerdos bilaterales firmados en el año 2004 sobre economía y cooperación se adicionaron con medidas específicas sobre refinanciamiento de deuda externa, aprovisionamiento de equipo para control de aduanas y proyectos de explotación de metales para exportación a China. La cooperación a través de instituciones educativas y de salud es altamente significativa, lo mismo que mediante seminarios sobre temas específicos de seguridad y sistema internacional.

China abastece el mercado cubano con manufacturas y le compra mineral de níquel, otros minerales, azúcar y melaza, pero no se compromete en el rumbo de algunas reformas de mercado iniciadas por Raúl Castro en 2010.

En octubre de 2011 se autorizó en Cuba la compraventa de vehículos, así como algunas actividades privadas de acuerdo a una lista de ocupaciones. Otras reformas económicas dadas a conocer en noviembre de 2011, permitirán la compra de viviendas en tanto se mantenga la condición de residentes permanentes, los pagos se hagan desde cuentas bancarias en el país y se paguen impuestos por la compra. La propuesta de reformas incluye eliminar los cuadernos de dotaciones racionadas de alimentos básicos y fortalecer las actividades privadas de pequeños productores, comerciantes y profesionales con el aumento de 180 mil licencias de operación. Con estas medidas se espera activar nuevas posibilidades de empleo para los 500 mil trabajadores que se calcula serán despedidos de actividades estatales en el futuro (Granma, noviembre 2011).

En las reformas políticas anunciadas en el Sexto Congreso del Partido Comunista Cubano del mes de abril de 2011, después de 14 años de no haberse realizado, se propuso limitar a diez años el periodo de encargos oficiales. Aunque la declaración más contundente es que el socialismo cubano, a 
pesar de las restricciones de sus circunstancias, se mantiene en una cautelosa "exploración de vías de desarrollo en sus condiciones nacionales para lograr [...] progreso en la construcción del socialismo bajo el liderazgo del Partido Comunista Cubano" (Granma, 29 de agosto 2011).

Es notoria la diferencia entre China y Cuba en el tono crítico respecto al papel de Estados Unidos como líder mundial y regional, pues si los gobiernos de Cuba y de otros países como RB de Venezuela, Ecuador, Bolivia y Argentina cuestionan y acusan directamente a Estados Unidos de intervención y persecuciones, China apela a la superioridad de su modelo económico frente a la organización occidental, pero mientras tanto avanza en la construcción de nuevas relaciones institucionales que le posibilitarían afectar las relaciones de poder en el continente, particularmente la influencia de Estados Unidos sin alinearse directamente a la línea dura de crítica.

República Dominicana no mantiene relaciones diplomáticas con China, pero los negocios se atienden a través de una oficina de representación permanente. Si se considera la importancia económica regional de ese país, se entienden los esfuerzos del gobierno chino de aceptar una representación permanente a pesar del reconocimiento a Taiwán.

Las más importantes relaciones económicas de China con países del Caribe se registran con Jamaica y Trinidad y Tobago, ya que como se señaló anteriormente representan parte importante del PIB de Caricom y de las exportaciones de bienes y servicios de la región.

Jamaica es una de las economías más grandes del Caribe, resulta importante porque es un país de intenso comercio exterior y líder del intercambio de servicios turísticos de la región (gráfica 1). El resultado bilateral de los últimos años es deficitario para Jamaica, lo cual se atribuye a la importación de manufacturas desde China.

Trinidad y Tobago es otro país importante para China en el Caribe, principalmente por la disponibilidad de recursos petroleros y de refinación así como con el abastecimiento de recursos energéticos entre países de la región y los acuerdos con Petrocaribe. ${ }^{10}$ Trinidad y Tobago es un país que en la última década ha aumentado el abastecimiento de recursos energéticos a países de la región y a Estados Unidos, lo cual le permite mantener superávit comercial

10. Petrocaribe ha sido impulsado por Venezuela desde 2005 como un mecanismo de integración y cooperación energética con canales alternativos de comercialización a las corporaciones petroleras globales. 


\section{Gráfica 1}

Intercambio comercial de Jamaica con China

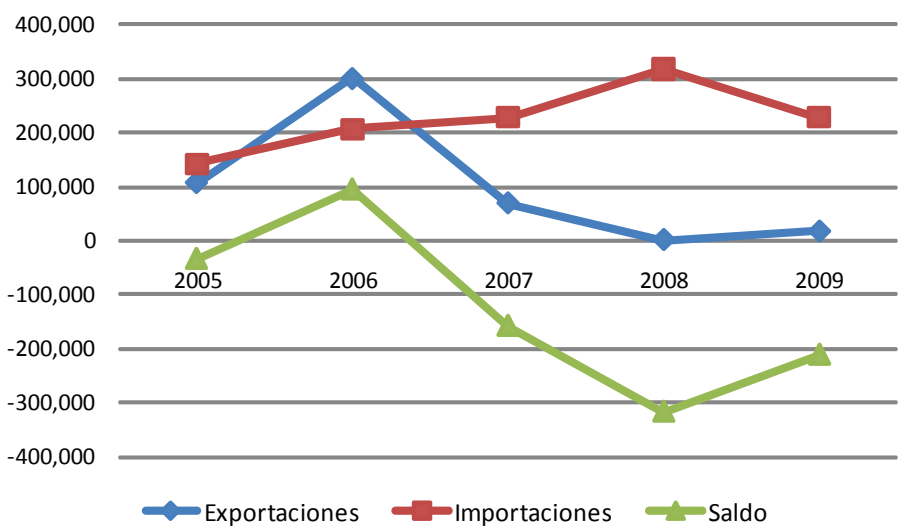

CEPAL, Panorama de la inserción internacional de AL y el Caribe, 2010.

desde 1993. Entre otros países con los que comercia, principalmente petróleo y productos petroleros, están Gabón y Rusia. China está en el grupo de países cuyo comercio resulta deficitario para Trinidad y Tobago, principalmente por la importación de productos manufacturados, con cifras que son superadas por las importaciones de manufacturas desde Brasil y Colombia (gráficas 2 y 3 ).

\section{Gráfica 2}

Trinidad y Tobago. Países con mayor aportación al superávit comercial

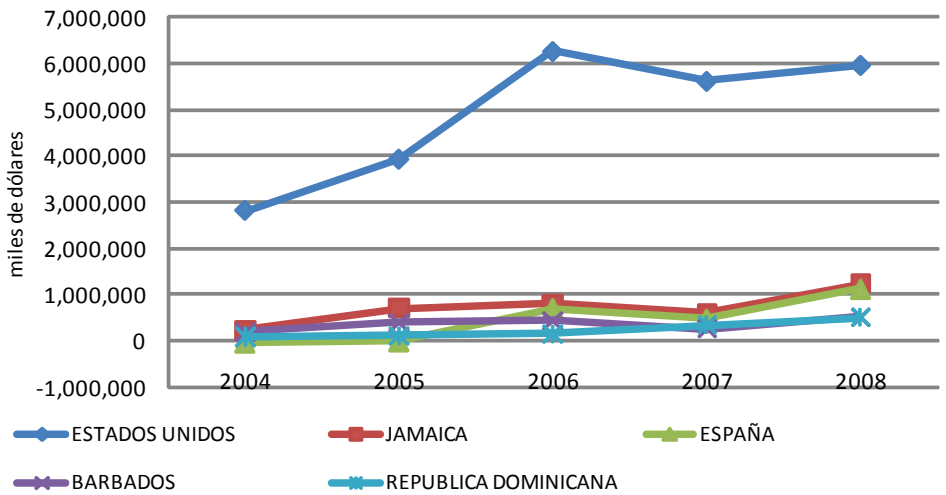

Fuente: Intal (http://www.iadb.org/es/intal/intal,1081.html). 


\section{Gráfica 3}

Trinidad y Tobago. Países con mayor aportación al déficit comercial

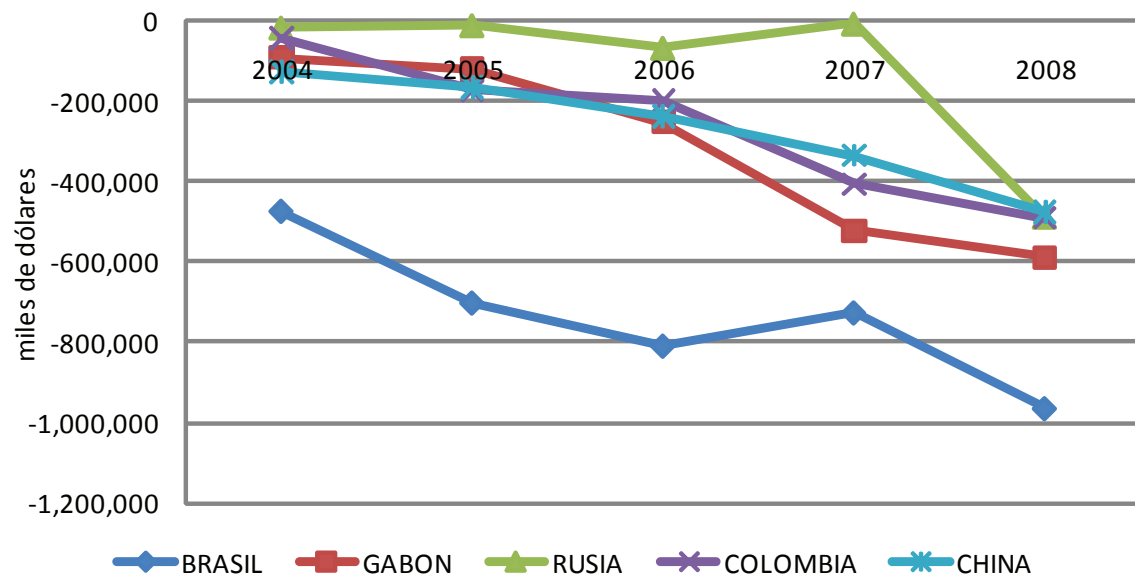

Fuente: Intal (http://www.iadb.org/es/intal/intal,1081.html).

Las relaciones bilaterales de Trinidad y Tobago con China han mejorado en los últimos años desde el establecimiento de un Acuerdo Económico y de Cooperación Técnica que llevó a la decisión, en junio de 2010, de establecer una embajada en Beijing para atender la creciente complejidad de intercambios diplomáticos y de negocios. En septiembre de 2011 el país caribeño fue sede del tercer encuentro de los países de la región con China. Otras categorías de actividades son proyectos de infraestructura y desarrollo con financiamiento del BID, entrenamiento de oficiales militares, actividades culturales, artísticas y de medicina tradicional china. Trinidad y Tobago reconoció el esfuerzo de ayuda económica de China en su apoyo a Haití en los últimos años.

La construcción de infraestructura y obras de considerable magnitud es un componente clave de la relación de cooperación de China con los países del Caribe. Se construyen estadios deportivos en Bahamas así como en Antigua y Barbuda, se desarrolla un centro de convenciones en Montego Bay en Jamaica, se rehabilita la refinería de Cienfuegos en Cuba, se otorgó un crédito por 40 millones de dólares para un proyecto de energía eléctrica en Guyana. Todos estos proyectos son ejemplo de áreas de negocios para empresas desarrolladoras y de construcción chinas con financiamiento de Eximbank. 
La relación de China con Bahamas incluye la mencionada construcción del estadio nacional, así como becas para estudiantes en China. Entre las categorías destacadas está la provisión de asistencia financiera directa, que ha sido superior a la recibida por el país caribeño de parte del BID. La buena disposición se expresó en la participación de Bahamas en la Expo Shanghai 2010 y en las visitas mutuas de oficiales de alto nivel desde el establecimiento de relaciones diplomáticas en 1992.

Barbados ha recibido desde China apoyo para proyectos turísticos, capacitación técnica para personal militar y algunas visitas de oficiales de gobierno y del Partido Comunista Chino (PCCh).

Una menor presencia china se percibe en los países de la OECO donde el titubeo entre reconocer a Taiwán o a China significa ventajas de negociación para el país involucrado; en este caso se encuentra Santa Lucía, que durante años osciló en sus relaciones diplomáticas entre ambas Chinas, hasta que la República Popular China decidió cancelarlas, destacando en el comunicado oficial la poca importancia económica de la isla y la falta de respeto a los principios de soberanía china.

La participación de China en tareas de apoyo internacional a través de los contingentes de "Cascos Azules" de la Organización de Naciones Unidas ha significado la presencia de Haití en misiones de paz desde el golpe de estado en 2004, misiones que se prorrogaron hasta meses después del terremoto de 2010 en tareas de ayuda humanitaria, saneamiento y reconstrucción del país.

Los recursos para el fomento al intercambio comercial y la expansión de actividades culturales, incluida la enseñanza del mandarín, son significativos. El componente cultural de conocimiento mutuo es importante. La larga experiencia de migración china ha generado comunidades chinas en ultramar y en países del Caribe cuya experiencia de contacto resulta significativa tanto para las relaciones con los chinos de Taiwán como con los chinos continentales.

Como se comentó anteriormente, en el Caribe son tres los países que mantienen reconocimiento diplomático a Taiwán: Belice, Santa Lucía y República Dominicana. En la lucha de China por desplazar a Taiwán en la esfera diplomática internacional, cada reconocimiento es un voto adicional en los foros internacionales. China tiene ya la mayoría de reconocimientos de los países del Caribe, en tanto Taiwán mantiene su ventaja entre los países centroamericanos.

Las relaciones de China con Caricom cubren un amplio espectro ya que son miembros de la organización con los que no mantiene relaciones diplomáticas. 
Por su parte, la OECO valora los esfuerzos de China por hacer que los países emergentes sean reconocidos globalmente, como parte de sus declaraciones políticas que no se transforman en medidas de distanciamiento con Taiwán.

China no tiene disputas comerciales registradas en la Organización Mundial de Comercio (OMC) con países del Caribe. El análisis de la información registrada en el mecanismo de solución de controversias de la OMC reporta que en realidad tiene y realiza pocas quejas y las que se formalizan son las relacionadas con Estados Unidos, Unión Europea y Canadá. El alto número de participaciones de China en controversias comerciales en la OMC corresponde a su adhesión como tercera parte en las controversias presentadas por otros países.

La ausencia de disputas comerciales entre China y países del Caribe es distinta si se considera la situación del conjunto de América Latina y el Caribe, ya que sin llegar a registrar disputas en la OMC se han expandido el número de investigaciones antidumping contra China por parte de Argentina, Brasil, Colombia y Perú (CEPAL, 2011). Este patrón es explicable a partir de la similitud en especialización manufacturera que tiene con estas naciones, así como con la disputa por mercados de exportación en terceros países. Tampoco hay que ignorar el vencimiento del periodo de limitaciones a China como parte de los acuerdos de su ingreso a la OMC. En los casos de México, Argentina y Brasil las disputas han sido principalmente por la penetración de mercados domésticos, que ha llevado a tensos periodos de aplicación de medidas bilaterales de salvaguarda y compensaciones antidumping.

\section{El debate sobre la presencia de China en el Caribe}

El impacto del crecimiento económico de China es indudable, al menos en tres distintos aspectos de la economía internacional: la demanda por insumos y alimentos que han elevado el precio internacional de algunos de ellos, la penetración de mercados domésticos con manufacturas que inhiben el proceso de industrialización doméstica y de integración regional, y la competencia por exportaciones a terceros mercados.

En esferas de reordenamiento del poder político de bloques y países a nivel internacional se identifican tres impactos: el ascenso de la promoción china en ser reconocido como un país responsable y que cumple con los acuerdos internacionales, el impulso para convencer a países en desarrollo de agruparse 
para negociar nuevas participaciones en los sistemas institucionales existentes y el permanente acoso a Taiwán en términos del reconocimiento internacional.

Luego de la crisis de 2008 se ha insistido en que la recuperación económica se ha originado en las economías emergentes, particularmente China. Además se reconoce que las posibilidades de ampliación del mercado doméstico pueden significar estímulos a la demanda de energéticos, minerales y algunos productos alimenticios que beneficiaría a países latinoamericanos que tienen ese patrón de exportaciones como Chile, Brasil, Argentina y Perú.

Las características de los impactos de China corresponden a las condiciones del país y las regiones; así encontramos competencia directa con México y Centroamérica, abastecimiento de recursos naturales con países de África, integración productiva regional con los países del Sudeste Asiático, entradas de capital desde Japón, Estados Unidos, República de Corea y la Unión Europea.

Esta multiplicidad de impactos y significados ha generado un debate respecto al estilo en que China acrecienta su presencia en distintas regiones en el mundo. Las opiniones forman un abanico de interpretaciones; desde la posición oficial china de ser socio estratégico y promotor de ventajas mutuas, hasta acusaciones de aplicar una posición neocolonial en la práctica y liberal en el discurso. Las interpretaciones están asociadas en gran parte a que los análisis se realizan desde la óptica de las economías involucradas, es decir, se eleva el sentido del impacto a partir de las características de las economías afectadas. ${ }^{11}$

Una posibilidad concreta para analizar la evolución y significado de la presencia china en una región, es considerar los flujos de capital a través de la inversión extranjera directa (IED), ya que es un indicador que al mostrar los flujos de capital traza la ruta del comercio y de los mercados de productos.

A partir del año 2000, China decidió promover su IED de salida para aumentar su presencia en el mundo. El primer elemento a considerar es que la IED originada en China es una fracción cercana a 4\% del total mundial en el año 2009, con una notable expansión en la última década más que el volumen involucrado respecto al total mundial.

De acuerdo a cifras de UNCTAD, entre 1999 y 2009 los flujos de salida de IED originados en China se han mantenido en aumento, siendo muy simila-

11. En este análisis omitimos los impactos de relaciones específicas asociadas a los intereses geoestratégicos de China, como sus relaciones con la República Popular Democrática de Corea, o algunos países de África. 
res a los de Hong Kong y dejando atrás a los provenientes de Taiwán. Esta tendencia es el elemento a destacar en la expansión financiera de China al exterior, pues corresponde a decisiones económicas y de negocios que también generan presencia política en busca de aceptación internacional.

\section{Gráfica 4}

IED. Flujos de salida (millones de dólares)

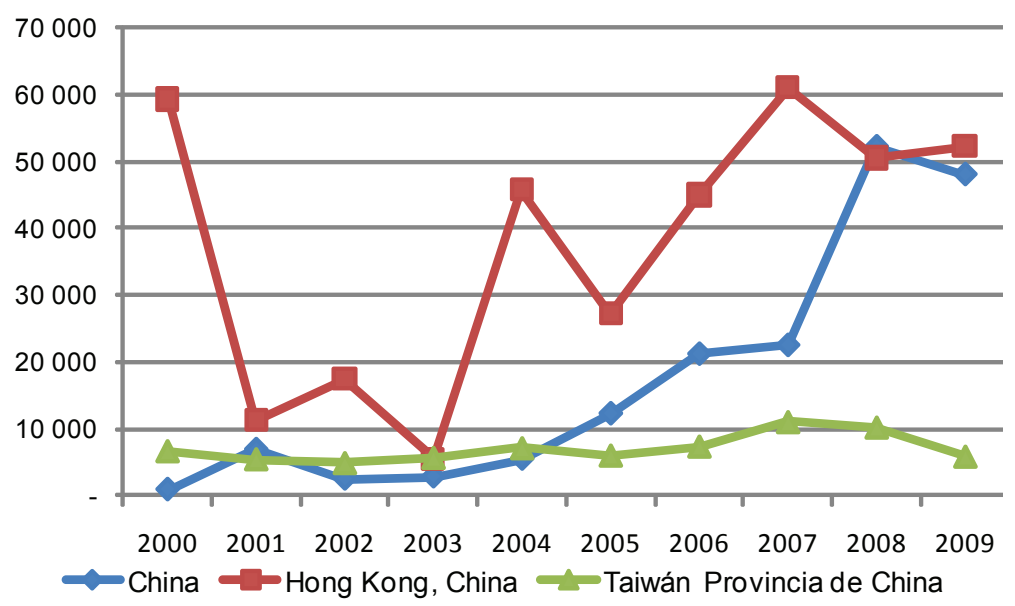

Fuente: UNCTAD. Base de datos IED.

La CEPAL señala que la IED de China en la región se ha dirigido a los paraísos fiscales de Islas Caimán e Islas Vírgenes Británicas (96\%) y a los países de mayor tamaño como Brasil, Perú, Argentina, RB de Venezuela y México (CEPAL, 2011: 24). Si bien señala que hay empresas chinas en proyectos de infraestructura para exportaciones en minería, recursos naturales y algunas manufacturas, los montos no son significativos respecto a los totales de IED de China o de otros agregados.

La presencia de China en el Caribe, como se ha comentado anteriormente, cubre una amplia gama de actividades de intercambio comercial, de negocios, muestras de cooperación económica, cooperación militar, declaraciones de apoyo político y ayuda humanitaria.

Los resultados comerciales y de inversiones de las relaciones de China con los países del Caribe señalan un volumen relativamente bajo del total de 
comercio e inversión que realiza China, pero son relevantes en la construcción de relaciones económicas y de cooperación. Fundamentalmente habría que reconocer la importancia de China como miembro del BID y la provisión de financiamiento vía Eximbank. Esta fuente de recursos es fundamental para algunos gobiernos de países del Caribe que pueden reconocer como positiva la presencia de China a pesar del impacto en sus estrategias de industrialización doméstica y regional.

El rechazo a la presencia y expansión de China proviene de reflexiones académicas e institucionales que perciben en los países receptores una falta de estrategia de largo plazo en la relación con China y destacan, a su vez, la claridad y habilidad de China en el uso de todos los mecanismos a su alcance para mantener su estrategia de proyección internacional ascendente.

La CEPAL es una institución que, con gran mesura, llama a considerar el riesgo que entraña ignorar las estrategias regionales de integración en América Latina y el Caribe, lo que puede llevar a que el aumento del comercio e inversión reproduzca y refuerce un patrón de centro-periferia con Asia y particularmente con China. Este llamado considera el proceso identificado como "re-primarización" de exportaciones y penetración de mercados domésticos de manufacturas (CEPAL, 2010).

En un documento posterior, la CEPAL revalúa y matiza su análisis respecto a China y sostiene que en el reordenamiento global económico y de gobernanza posterior a la crisis de 2008, China ha adquirido mayor importancia. De ahí parte una reconsideración sobre las posibilidades de integración productiva, comercio e inversión con los países de América Latina y el Caribe (CEPAL, 2011). Lo que se mantiene es el señalamiento de una "limitada diversificación" exportadora hacia los mercados chinos a pesar de que haya sido, en el año 2010, el destino de 8\% de las exportaciones del continente (Estados Unidos $41 \%$ y Europa 13\%) (CEPAL, 2011).

Los temas de desarrollo económico, creación de empleo y mejora de condiciones sociales que deberían ser fundamentales para el proyecto de los países, son relegados por negocios de corto plazo, soluciones de cooperación y ayuda a partir de decisiones de apoyo político a los intereses de China.

Hay que agregar el papel del acoso de China a Taiwán, lo que significa utilizar todas las artimañas diplomáticas e incluso ilegales para cambiar el reconocimiento que algunos pocos países en el Caribe mantienen hacia Taiwán. En Centroamérica, por ejemplo, son conocidos los casos de corrupción entre oficiales de gobierno, empresarios, grupos y personas que puedan impulsar 
el cambio en el reconocimiento diplomático. Esto ha significado también un apoyo a países que, entre tanto deciden si cambian o no su reconocimiento, obtienen ventajas tanto de Taiwán como de China.

Haro sostiene que China está construyendo instituciones y acuerdos regionales para avanzar en la construcción de un contexto regional que le sea favorable, en furiosa competencia con rivales como Estados Unidos, la Unión Europea y por supuesto Taiwán. En esta competencia se utiliza comercio, cooperación, ayuda y símbolos que incluyen comunidades chinas asentadas desde hace tiempo en los países de la región, así como el establecimiento de centros de investigación en ciencias sociales sobre Centroamérica y el Caribe (Haro, 2008).

Es a partir de estas consideraciones que adquiere relevancia la discusión del modelo chino y las posibilidades de China de convertirse en un perfil económico y cultural que prevalezca en otras regiones distintas de la del Asia Pacífico.

Manfred Mols sostiene que un problema básico para la afirmación de este supuesto modelo chino es la falta de perfil unitario asiático, así como la rivalidad por el liderazgo y la incapacidad por incorporar el pluralismo político y social. Afirma también que China no ha desarrollado ningún sentimiento de responsabilidad mundial más allá de un centrismo autoritario, que ignora contradicciones entre nacionalidades más allá del autoritarismo del Estado patriarcal que prescribe las tradiciones de un pasado feudal (Mols, 2010).

En resumen, constatar que China respeta las reglas internacionales no significa sino cumplir el mínimo convencional para ser considerado participante, lo cual no construye un liderazgo que pueda ser incluyente respecto a los intereses de otros participantes.

Los resultados de las negociaciones de las modificaciones de cuotas y votos en el FMI son un ejemplo; el aumento en la capacidad de negociación en ese organismo benefició a China, India, Brasil y algunos países petroleros. La mejoría en la participación individual en el FMI no se ha reflejado en los mecanismos de operación institucional que puedan significar ventajas para otros países subdesarrollados.

La presencia de China en el Caribe es el ejercicio de este país en la búsqueda por asegurar el logro de sus metas y propósitos de largo plazo, de ahí que las ventajas de su presencia y los daños de su competencia deban verse desde la óptica de los intereses de largo plazo de las economías receptoras. my 


\section{Bibliografía}

Bárcenas, Alicia (2011), "Contamos con China para adelantar la gobernanza económica mundial”, Discurso por la visita de Xi Jinping a la sede de CEPAL, 10 de junio.

BID (2005), "Compitiendo con China en el Comercio global", Ideas para el desarrollo en las Américas, enero-abril.

BID (2005), "Hacia el futuro: cómo enfrentar la competencia china", Ideas para el desarrollo en las Américas, enero-abril.

BID (2011), "IDB-China Eximbank join forces to set up infrastructure facility and public - private investment fund in Latin America and Caribbean", News releases, marzo 28.

CePAl (2010), La República Popular China y América Latina y el Caribe: hacia una relación estratégica, Santiago de Chile, mayo.

CePAl (2011), La República Popular China y América Latina y el Caribe: hacia una nueva fase en el vínculo económico y comercial, Santiago de Chile, junio.

CEPAl (2010), Panorama de la inserción internacional de América Latina y el Caribe 2010-2011. Crisis originada en el centro y recuperación impulsada por las economías emergentes, Santiago de Chile, agosto.

CEPAL (2011), Panorama de la inserción internacional de América Latina y el Caribe 2010-2011. La región en la década de las economías emergentes, Santiago de Chile, septiembre.

CEPAL, INIE, PNUD (2004), Cuba a principios del Siglo 21, México, abril.

Correa López, Gabriela (2009), "China en África”, Análisis Económico, vol. XXIV, núm. 56, México DF: UAM Azcapotzalco, segundo cuatrimestre, pp. 203-228.

Correa López, Gabriela y Juan González García (2006), "La inversión extranjera directa: China como competidor y socio estratégico", Nueva Sociedad, núm. 203, Buenos Aires, pp. 114-127.

Gobierno de la República Popular China, “China's Policy Paper on Latin America and Caribbean". Disponible en: http://www.gov.cn/english/ official/2008-11/05/content_1140347.htm.

González García, Juan y Gabriela Correa López (2009), “América Latina en el proyecto global de China”, Comercio Exterior, vol. 59, núm. 12, México: Bancomext, pp. 979-993.

Haro Navejas, Francisco Javier (2008), "Cambio en el equilibrio de poder en América Latina: el impacto chino en Cuba". Ponencia presentada en la 
VIII Reunión de la Red de Estudios de América Latina y el Caribe sobre Asia Pacífico, Bogotá.

Lampton, David M. (2008), The Three Faces of Chinese Power. Might, Money, and Minds, Berkeley: University of California Press.

Lora, Eduardo (2006), "Should Latina America Fear China?", Working paper, Research Department, núm. 531, Inter-American Development Bank, marzo.

Mols, Manfred (2010), “¿Del siglo norteamericano al siglo del Pacífico asiático?”, México y la Cuenca del Pacífico, vol. 13, núm. 39, septiembre-diciembre, México: Universidad de Guadalajara, pp. 13-45.

People's Republic of China (2007), MOFCOM “Joint Declaration of the 2ND China - Caribbean Economic and Trade Cooperation Forum”, septiembre, 10. Ríos, Xulio (2008), “China y Cuba: tiempo de herejías”, El País. Foro Ibero Asiático, España, 11 de agosto. Disponible en: www.iberoasia.org. UNCTAD, Trade and development report 2010, Ginebra, Suiza.

Fuentes electrónicas

Instituto para la Integración de América Latina, Banco Interamericano de Desarrollo. Disponible en: www.iadb.org.

Caricom. Países miembros y asociados. Disponible en:

www.caricom.org, www.bahamas.gov.bs, www.barbados.gob.bb, www.belize. gov.bz, www.jis.gov.jm, www.sr.net, www.ttconnect.ov.tt.

Jamaica Observer News. Disponible en: www.jamaicaobserver.com/news/ Chin-announces-billion-dolar-initiative-for-c.

Organización de Estados del Caribe Oriental. Disponible en: www.oeco.

Organización Mundial de Comercio. Disputas comerciales. Disponible en: www.wto.org.

Periódico Granma. Noticias y discursos. Disponible en: www.granma.cu.

Sistema de la Integración Centroamericana. Secretaría, Sistema de Estadísticas de Centroamérica, 2010. Disponible en: http://estadisticas.sieca.int/ Estadisticas/MenuEstadisticas.asp?Base=Paises

Xinhuanet. Disponible en: http://english.mofcom.gov.cn. 


\section{Anexos}

\section{Mapa 1}

Países en la Cuenca del Caribe

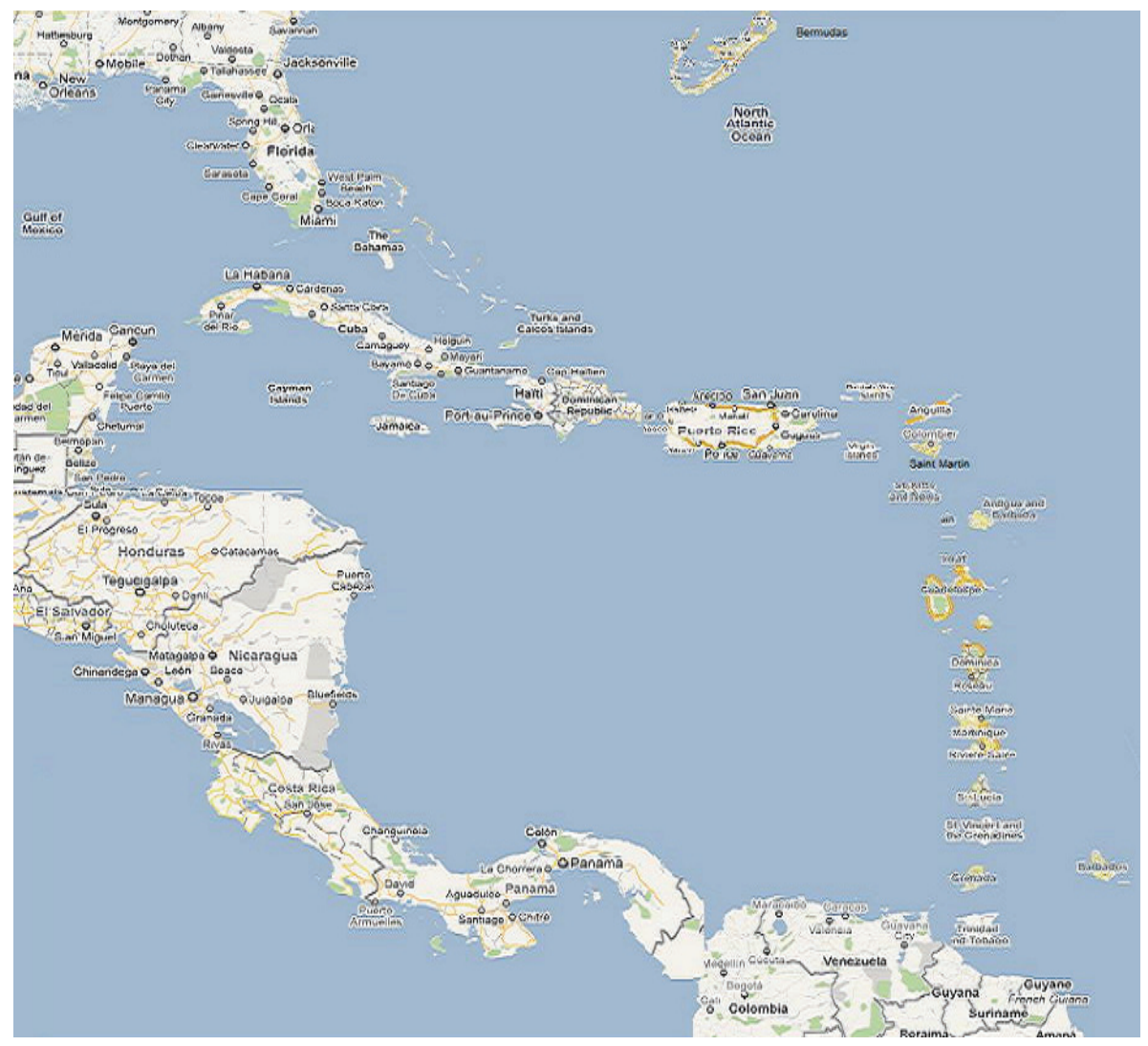

Fuente: elaboración LARC a partir de mapas en Google. 


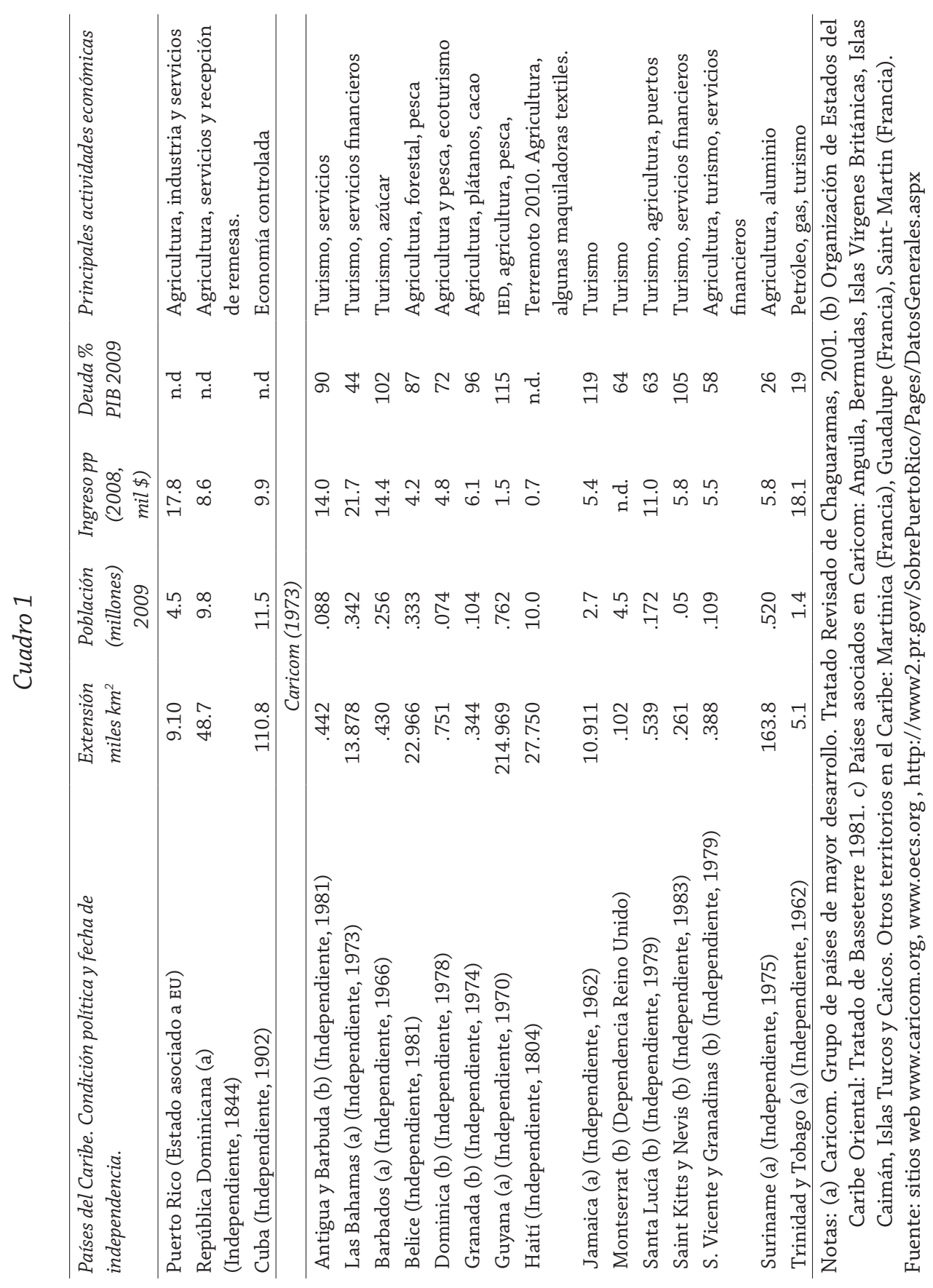




\section{Japón ante la nueva configuración}

de Asia del Pacífico

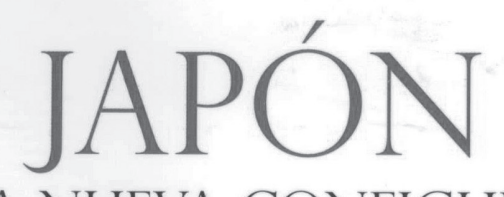

ANTE LA NUEVA CONFIGURACIÓN DE ASIA DEL PACÍFICO

PROACTIVIDAD Y REACTIVIDAD ANTE UN ORDEN INTERNACIONAL FLUIDO

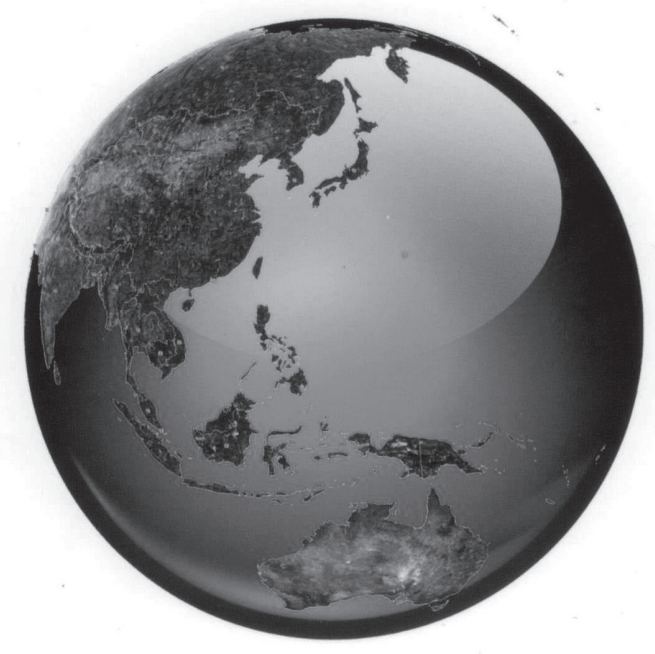

JUAN JOSÉ RAMÍREZ BONILLA DANIEL TOLEDO BELTRÁN CARLOS USCANGA PRIETO COORDINADORES

EL COLEGIO DE MÉXICO 